\title{
TIEMPO DESQUICIADO Entrevista a Darío Sztajnszrajber
}

\author{
DERANGED TIME \\ Interview with Darío Sztajnszrajber
}

Sofía Delle Donne / sofiadelledonne@gmail.com Instituto de Investigación en Producción y Enseñanza del Arte Argentino y Latinoamericano

Facultad de Artes Universidad Nacional de La Plata. Argentina

Federico Santarsiero / federicosantarsiero@gmail.com Facultad de Artes. Universidad Nacional de La Plata. Argentina

Recibido: 10/4/2020

Aceptado: 7/7/2020

\section{RESUMEN}

En la siguiente entrevista, Darío Sztajnszrajber desarrolla la noción de tiempo en sentido filosófico $y$, en particular, las características distintivas que adquiere este concepto en medio de la pandemia por el coronavirus. A razón de ello relaciona el tiempo (o los tiempos) con la cotidianidad, la política y el arte.

\section{PALABRAS CLAVE}

Darío Sztajnszrajber; filosofía; tiempo; pandemia

\section{ABSTRAC}

In the following interview, Darío Sztajnszrajber develops the notion of time in a philosophical sense and in particular the distinctive characteristics that this concept acquires in the coronavirus pandemic. Because of this, he relates time (or times) with daily life, politics and art.

\section{KEYWORDS}

Darío Sztajnszrajber; philosopy; time; pandemic 
Darío Sztajnszrajber es licenciado en Filosofía por la Universidad de Buenos Aires (UBA). Ha sido docente en todos los niveles de la educación formal. Es ampliamente conocido por su labor como divulgador de la filosofía, por la cual obtuvo el premio Konex en el 2017. Su libro más reciente es Filosofía a martillazos (2019). Mentira la verdad (2011) y Ocho Filósofos (2016) son algunas de sus producciones audiovisuales. También se desempeña como conductor radial.

En tiempos de pandemia los pensadores y las pensadoras más importantes de la actualidad han reflexionado sobre esta crisis mundial. Giorgio Agamben intercambia ideas con Jean Luc Nancy; Bifo Berardi relata su regreso a Lisboa y lo denomina "Crónica de la Psicodeflación»; Enrique Dussel y Álvaro García Linera dialogan por el canal de YouTube de un portal de noticias mexicano; Judith Butler escribe sobre el coronavirus y el poder, mientras que Paul Preciado afirma que la frontera es la mascarilla.

Desde la Argentina, Darío Sztajnszrajber nos invita diariamente a ingresar al terreno de un pensamiento situado por medio de publicaciones organizadas en una agenda cargada. Con un perfil por demás dinámico, actualmente lleva adelante dos programas radiales (Demasiado Humano, en Futurock, y Lo intempestivo, en Nacional Rock). Además, junto con la periodista Ángela Lerena, conduce un programa en la multiplataforma Seguimos Educando - que forma parte del programa nacional para promover la continuidad de la enseñanza en tiempos de covid-19-, donde da clases para el nivel secundario. Su presencia en Instagram tiene un gran número de seguidores, realiza vivos semanales como el diálogo con el ministro nacional de Educación, Nicolás Trotta o con el historiador Felipe Pigna. Por último, sin exagerar, podríamos definir sus espectáculos teatrales (en tiempos anteriores al coronavirus) como giras federales de militancia filosófica. Una de sus últimas participaciones en medios gráficos fue un artículo en el diario Página 12 que se denominó «El tiempo como oportunidad» (2020).

En medio de todas sus actividades le propusimos continuar dicha publicación en esta entrevista. Agradecemos que el 7 de mayo del intempestivo 2020 se haya tomado un momento para charlar, vía WhatsApp, con Octante. 
El tiempo recorre la narrativa filosófica porque es uno de los grandes temas existenciales que tiene que ver con eso que trabaja siempre la filosofía, que son aquellos acontecimientos que se han vuelto tan naturalizados en nuestros cotidianos que no los analizamos en el despliegue de sus diversas perspectivas. Terminamos dando por supuesto el accionar, la existencia de fenómenos, que en realidad puestos a distancia son mucho más problemáticos o extraordinarios de lo que creemos, en el sentido que exceden el orden. Uno de estos fenómenos es el tiempo. Lo damos por supuesto porque vivimos atravesados por él, pero ni bien tomamos distancia y nos ponemos a pensar, nos damos cuenta que estamos dando por obvia toda una serie de prenociones que terminan constituyendo una forma específica de la percepción del tiempo que no es la única. Hay otras formas de pensar el tiempo: en la complejidad de la tensión entre una instancia subjetiva o una existencia objetiva/cósmica, independientemente del ser humano, o en relación con su linealidad, que es el paradigma que ha hegemonizado la lectura del tiempo y que no nos permite visualizar que hay otras dimensiones de lo temporal que exceden esa linealidad.

¿Hay un tiempo o hay tiempos?

Depende mucho de la definición o del paradigma que uno aporta para hablar del tema. Que haya muchos tiempos solo se lo puede pensar si nos salimos de la perspectiva más cuantitativa que entiende al tiempo como único. En ese sentido, hay un abordaje científico que a mí se me escapa (la idea de que pueda haber tiempos simultáneos funcionando puede ser producto de la imaginería literaria, aunque calculo que en términos científicos se podría indagar esa posibilidad). Desde la filosofía, lo más interesante es postular esa distensión del tiempo cuantitativo hacia un escenario cualitativo. Que no pasa solo por esta idea de que en realidad la percepción del tiempo, al ser subjetiva, escapa de la medición concreta, por ejemplo: cinco minutos en diferentes situaciones existenciales pueden ser mucho o poco. Eso es claro. Además de eso hay una dimensión cualitativa en la que el tiempo no solamente es vivido como tiempo-de-medición y, por lo tanto, de productividad. Esta idea que se ha instalado de aprovechar el tiempo, de hacerlo productivo, puede distenderse hacia un tiempo interrumpido. 
Se trata de una idea de pensar al tiempo más como una especie de paréntesis, donde tenemos una conexión con la temporalidad en la que sin estar corriendo ni midiendo ni cronometrando, somos conscientes de estar viviendo un determinado momento temporal en el que sucede algo que nos transforma. Esto no es más que la idea griega del tiempo como ocasión. El dios Kairós, que es justamente una representación cualitativa del tiempo, nos dice: "este es un tiempo para hacer tal cosa, para estudiar, para estar solo", lo que hace que allí la percepción del tiempo no tenga que ver con una medición concreta. Podemos decir entonces que sí hay tiempos. Porque como mínimo tenemos el tiempo consensuado públicamente y después el modo en que uno se relaciona con él. ¿No? Desde esta perspectiva se puede ver que hay más de un tiempo.

Esta especie de parate en el tiempo que implica el momento de aislamiento social, ¿podría ser una oportunidad para pensar un tiempo-otro en nuestras vidas?

La cuarentena lo que hizo fue desquiciar el tiempo, por retomar esa frase de William Shakespeare que aparece en Hamlet [1603] (1999): «El tiempo está fuera de quicion(p. 35). Sobre todo, porque el protagonista la enuncia en el momento en que se encuentra con el fantasma de su padre y lo que le sale decir es eso: que el tiempo está desquiciado. Porque obviamente, si alguien que está muerto aparece... Tal vez lo que deberíamos preguntarnos es si la cuarentena, además de desquiciarnos el tiempo (como el padre muerto al príncipe Hamlet), no nos ha convertido a todos en fantasmas y, de algún modo, estamos en una zozobra temporal que no nos permite apropiarnos de lo que hasta ahora ha sido una vida ordenada. El fantasma rompe los límites binarios, no nos olvidemos que es bastante subversivo, es desestructurante, nunca se siente cómodo consigo mismo. Me parece que ahí hay una figura interesante para pensarnos como fantasmas en contraposición a lo que una sociedad de la productividad elige para nosotros. No creo que un fantasma sea productivo, todo lo contrario, porque está viviendo fuera de un tiempo lineal y de un tiempo al que se le exige una eficacia. ¿No? Aunque el fantasma sí está atravesado por una carencia imposible, está transido por la necesidad de resolver algo pendiente que tal vez nunca se resuelva. Hay algo en esa cosa pendiente, irresoluble, que también se nos presenta en esta distensión del tiempo de la cuarentena. Tal vez 
la vida que veníamos llevando a cabo hasta que esto explotó no era una vida muy feliz o, por lo menos, no era muy genuina.

¿En América Latina esa oportunidad es solo de supervivencia o puede ser también una ocasión para la sublevación?

Soy muy escéptico con relación a las formas políticas y sociales en que pueda devenir esto. Más allá de que muchos puedan encontrarse en otra dimensión existencial a partir de este parate, lo que va a terminar sobreviviendo, lamentablemente, es una narrativa neoindividualista, aislacionista, que hace del otro un agente de contagio permanente e inminente. Porque algún día la pandemia va a terminar, pero lo que no va a terminar es esa relación impúdica con el otro, al considerarlo siempre un peligro inminente. Ya veníamos de poner al otro en su lugar, el otro ya era un agente de contagio, simbólico, metafórico. Ahora se volvió un agente de contagio real. Como ya dije, de las derivaciones de esto en América Latina yo soy bastante escéptico, por la particularidad de cómo se visualiza en nuestra tierra la figura del otro. Ya veníamos viviendo en distintos confinamientos, sobretodo en nuestros territorios: cuando pensamos a esos otros excluidos, pienso que siempre ese vínculo y esa distancia tuvo que ver con ver en el otro un potencial agente de contagio. Ojalá cambie, pero la veo difícil.

¿Cómo puede pensarse en este contexto la trama temporal del arte?

Creo que este tiempo-otro realmente puede ser una buena oportunidad para pensar la existencia por fuera del paradigma productivo y también para pensarla desde una perspectiva estética, en el sentido foucaultiano de estetización de la existencia o de reconciliación vanguardista del arte con la vida. En una sociedad donde la desigualdad es tan manifiesta cuesta más, pero pienso que hay una posibilidad de pensarse a uno mismo más poetizado. De algún modo, esta incertidumbre generalizada también ha vuelto a poner la incertidumbre como motivación, la poesía es un lugar donde ella se hace palabra. El lugar que la poesía inaugura me parece interesante para un desarrollo artístico, más ambiguo, no del arte como técnica y no como práctica productiva. Entiendo que al mismo tiempo la capacidad de concentración en este colapso de lo temporal es manifiesta porque se vuelve difícil ponerse a escribir un libro, a pintar o a producir videos. Se complica la realización de esa asociación histórica

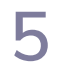


en la cual en el arte se produce esa juntura entre la inspiración o la expresión con la posterior presentación creativa específica en términos materiales. Pero sí hay como un impulso artístico al que se le puede dar lugar y que tiene que ver con pensarnos desde todas las aperturas que genera eso. Visualizarnos más cerca de una poesía que de una tarjeta de crédito.

\section{REFERENCIAS}

Canal Encuentro (Productora) y Destito, P. (Director). (2011). Mentira la verdad [Serie televisiva]. Disponible en http://encuentro.gob.ar/ programas/serie/8023/6939

Facultad Libre. (9 de marzo de 2016). Ocho filósofos [Archivo de video]. Disponible en https://www.youtube.com/playlist?list=PLGDZ QYren6SVICZKaQyJtw5XLu6Xq2Dx2

Shakespeare, W. [1603] (1999). The tragedy of Hamlet, prince of Denmark [La tragedia de Hamlet, el príncipe de Dinamarca]. Recuperado de https://www.w3.org/People/maxf/XSLideMaker/ ham let.pdf

Sztajnszrajber, D. (2019). Filosofía a martillazos. Ciudad Autónoma de Buenos Aires, Argentina: Paidós.

Sztajnszrajber, D. (29 de marzo 2020). El tiempo como oportunidad. Página/12. Recuperado de https://www.pagina12.com.ar/256032el-tiempo-como-oportunidad 